\title{
Association between Communicative Competence in English and Organizational Effectiveness in Dental Hygienists
}

\author{
Myeonghwa Park ${ }^{1}$, Jong-Hwa Jang ${ }^{1,2}$ \\ ${ }^{1}$ Department of Oral Health, Graduate School of Health and Welfare, Dankook University, Korea \\ ${ }^{2}$ Department of Dental Hygiene, College of Health Science, Dankook University, Korea
}

\begin{abstract}
Objectives: In the time of a globally connected world, the number of foreign patients using dental hospitals in Korea is steadily increasing. This study aims to find the educational direction for strengthening the communicative capacity of dental hygienists, and to identify and understand the correlation between dental hygienists' English communication proficiency and frequency and organizational effectiveness so that the results may be used as basic data for the development of specific purpose curriculum for the hygienists.
\end{abstract}

Methods: The subjects of this research were all of dental hygienists participating in a study group organization for dental English and 195 dental hygienists working at dental hospitals and clinics in Seoul that treat foreign patients. A structured questionnaire was distributed both on- and offline to survey English communication proficiency and frequency of dental hygienists and organizational effectiveness.

Results: There was a strong positive correlation between English communication proficiency and frequency $(r=0.682, p<0.01)$, and it was determined that higher English communication proficiency and frequency led to greater job satisfaction $(\mathrm{r}=0.357$, $\mathrm{p}<0.01)$ Dental hygienists who had experience in giving dental assistance to foreigners displayed higher job satisfaction $(\beta=$ 0.179 ), and the effect was more evident in the order of those working at dental hospitals ( $\beta=0.135)$ and according to English communication proficiency ( $\beta=0.134$ ). The coefficient of determination of this study is $33.5 \%$.

Conclusions: Job satisfaction of dental hygienists in charge of treating foreign patients was found to be very low. As it has been determined that job satisfaction increases with higher English communication proficiency when treating foreign patients, it is deemed necessary to develop and implement education and relevant programs that can improve English communication proficiency of dental hygienists working at dental hospitals and clinics that are frequented by foreign patients.

Keywords: English communication, Foreign patient, Organizational commitment, Job satisfaction, Dental hygienist

Copyright (C) 2021. Korean Academy of Preventive Dentistry. All rights reserved.

This is an Open Access article distributed under the terms of the Creative Commons Attribution Non-Commercial License (http://creativecommons.org/licenses/ by-nc/4.0) which permits unrestricted non-commercial use, distribution, and reproduction in any medium, provided the original work is properly cited. 